\title{
Development and usability evaluation of a nutrition and lifestyle guidance application for people living with and beyond cancer
}

\author{
Gareth Veale ${ }^{1}$, Huseyin Dogan ${ }^{1}$ and Jane Murphy ${ }^{2}$ \\ ${ }^{1}$ Faculty of Science and Technology, Bournemouth University, UK \\ ${ }^{2}$ Faculty of Health and Social Sciences, Bournemouth University, UK \\ \{i7765155, hdogan, jmurphy\} @bournemouth.ac.uk
}

\begin{abstract}
There is a need to provide accessible information for health care professionals and for people living beyond treatment. Mobile and digital health technologies provide an ideal platform to access diet and nutrition guidance that is both trusted and evidence-based and so that people know how to alter and monitor eating patterns and behaviours to improve the quality of life. Participatory design and usability evaluation approaches have been utilised to develop a nutrition and lifestyle guidance smartphone application for both people living with and beyond cancer, and for health care professionals involved in advising such patients. The challenges centred on the design, development and evaluation of the first version of a new mobile application named 'Life Beyond' are presented. This proof of concept application aims to centralise evidence-based nutrition and lifestyle guidance for those living beyond cancer. It enables users to obtain guidance and information, create and track nutrition and activity related goals and track their progress in the completion of these goals. Consistent feedback from participatory design and usability evaluations drove this research and helped to create an initial solution that met the user expectations. The System Usability Scale (SUS) score of 67.69 denotes an 'average' usability and hence further development. More research of extensive end user engagement is needed before an optimal solution is disseminated.
\end{abstract}

Keywords: Nutrition, Lifestyle, Digital Health, Cancer, Participatory Design, Usability.

\section{Introduction}

The number of people living beyond a cancer diagnosis in the UK has doubled in the past 40 years due to earlier detection and improved treatments [1]. People living with and beyond a diagnosis of cancer are all at increased risk of cancer recurrence as well as other chronic conditions such as diabetes, osteoporosis and cardiovascular dise ase [2]. Nutrition is an important modifiable factor that could reduce these risks, thereby promoting long-term health. Dietary change may also impact quality of life, particularly those diagnosed with prostate, breast and colorectal cancers [3]. The World Cancer Research Fund (WCRF) has a Continuous Update Project that provides 
an analysis of International research on diet, nutrition and physical activity and weight in relation to cancer risk and survival. In 2018 the WCRF provided an update of their recommendations for a healthy population to be a healthy weight, be physically active, eat a diet rich in wholegrains, vegetables, fruit and beans, limit the consumption of 'fast foods' and other processed foods high in fat, starches and sugars, red and processed meat, sugar sweetened drinks, alcohol consumption and not to use supplements [4]. Currently, it is recommended that people living after a cancer diagnosis should follow these, whenever possible, unless advised otherwise by a qualified health professional. Following a cancer diagnosis, people become strongly motivated to modify their diet behaviours to increase well-being, maintain health and prevent recurrence $[5,6,7]$. Yet, studies have shown that they have received unsatisfactory experiences of nutritional care from health professionals and received very little, or confusing advice on how best to approach nutrition for their cancer and for the different stages of their treatment journey $[8,9,10]$. They are more likely to seek and obtain dietary information from unreliable sources often via the internet that might be unsafe or explore complementary and alternative medicine including nutritional therapies despite the absence of scientific evidence from controlled clinical trials to support their claims $[11,12]$. In 2015 , a patient survey undertaken by the NIHR Cancer and Nutrition collaboration showed that patients were not receiving the advice and support they want. Patients reported needing "clear, uncomplicated information"; needing mechanisms to "overcome conflicting advice and tailored, cancer-specific advice that is fact-based" and to be "given information, rather than needing to conduct their own research" [13].

Health care professionals are not trained to provide dietary advice or are not aware of the relevant guidelines that exist. They want further support in areas such as: dietary advice for specific cancers and cancer stage, assessment of nutritional status, alternative dietary approaches, and use of dietary supplements in cancer [14].

There is a need to provide accessible information for health care professionals and for people living beyond treatment $[10,13]$. Mobile digital health technologies provide an ideal platform to access diet and nutrition guidance that is both trusted and evidence-based and so that people know how to alter and monitor eating patterns and behaviours to improve quality of life and potentially reduce the risk of cancer recurrence. The popularity of smartphones and the increasing adoption rates of $\mathrm{M}$ Health applications reinforced the need to utilise such platforms for nutrition and lifestyle guidance. Existing nutritional applications are also reviewed in this paper to understand whether they promote behaviour change.

This paper presents the challenges faced when designing, developing and evaluating the first version of a new mobile application named 'Life Beyond'. This includes the feedback from the pilot studies, participatory design study and usability evaluation of the first version of the application with health care professionals. The paper also presents the limitations of existing nutritional applications to produce a system in line with end user requirements. 'Life Beyond' aims to centralise evidencebased nutrition and lifestyle guidance for those living beyond cancer and debunk the nutrition myths in an accessible format. It enables users to obtain guidance and information, create and track nutrition and activity related goals and track their progress in the completion of these goals. The section in the paper are as follows: existing nutrition applications are covered in section two; the method utilised 
including participatory design and usability evaluations are described in section three; the results including the SuS score are presented in section four; discussions centred on the solution and its limitations are covered in section five; and the final section is the conclusion where the shift toward a recommender system app based on user profiling is highlighted as future work.

\section{Nutrition and mobile health}

Mobile health applications offer an incredible opportunity to increase the accessibility of healthcare. Remote medical diagnoses are an example of an area being developed heavily in order to reduce healthcare costs and decrease face to face communications between health care professionals and patients [15]. A variety of nutritional applications have become popular, helping users track their daily food consumption and monitor their progress in achieving fitness related goals. Example of these are reviewed below in an attempt to infer the strengths and limitations of each.

MyFitnessPal [15] is an application that enables users to track eating habits on a daily basis. This is offered through a feature that enables users to create a food diary. Subsequently, energy (calorie) intake and consumption of micro and macronutrients are automatically calculated. Users have the ability to personalise dietary goals and track fitness related progress through weight monitoring. This application incorporates goal setting and an extensive progress tracking feature, both important behavioural change techniques. However, as the name suggests, this application is targeted towards the fitness industry. Though it may be applied to monitor dietary behaviours and patterns, it is in no way specific to cancer.

Daily Dozen [16] has been built to serve as a companion to the book 'How Not to Die' authored by Dr Michael Greger M. D. Users are shown a list of foods that, if consumed as part of a healthy lifestyle, can help to prevent major chronic diseases. Users have the option to select each item to obtain additional information around serving sizes and foods that fall under each category. Though this application is very simple it offers an extremely useful tool for ensuring important food groups are consumed on a daily basis. The daily progress feature provides users with an incentive to consume each of recommended foods and can be categorised as goal setting. Again, this application is not cancer specific and it does not offer information related to cancer and cancer related nutrition. Medscape [17] is an application aimed at health care professionals, it provides a myriad of information ranging from prescriptions to operating procedures. This application does not promote behaviour change and is not aimed at those living beyond cancer. However, it offers an example of how evidence-based and academic research can be presented to users in a userfriendly and positive format. Patient specific data has also been incorporated into other areas for nutrition consultation and benefit demonstrated to support selfmonitoring for weight loss and measure dietary intake $[18,19]$ and glucose monitoring in type 1 diabetes [20].

Researchers have also developed and tested a mobile phone app to reduce the risk of breast cancer through healthy behaviours by recording dietary intakes and activity levels and connectivity with commercially available products for monitoring and tracking physical activity and intake [21]. Moreover, a pilot study [22] has explored 
the feasibility and applicability of a mobile phone app to assess dietary behaviours in oncology patients who needed to increase dietary intake following cancer diagnosis and treatment. By tracking daily dietary behaviours, the participants were more likely to reach their nutritional goals.

Goal setting, monitoring indicators and tracking features have been documented to drive successful M-health apps [22]. Thus personalised guidance and information can create a more intimate experience likely to be incorporated into a user's lifestyle. However there remains no smartphone application that has been specifically designed to provide nutrition and lifestyle guidance for both people living with and beyond cancer, and for health care professionals to help advise their patients.

Time should be spent understanding consumer requirements and expectations, using this data to inform design decisions and to encourage self-monitoring to meet this gap [24]. Consequently, the following section provides an overview of the methods used to involve users in the development process of the Life Beyond application.

\section{Method}

\subsection{Participatory Design supporting the implementation}

Creating an excellent User Experience (UX) can be defined as 'the designing of applications that a person of average ability and experience can figure out how to use the thing to accomplish something without it being more trouble than it's worth' [25]. UX is important in capturing the attention of users and if done poorly can force users to look elsewhere. Participatory Design (PD) is an approach committed to directly involving end users in the design of new technologies [26]. PD is receiving attention in the behavioural change research. For example, PD is used to develop a digital toolkit to promote quality of life of people with multiple sclerosis through using cognitive behavioural therapy [27]. Although we used PD with two Health Care Professionals due to limited resources and time, it was still invaluable in designing the features for the Life Beyond application.

Agile has been used as the software development methodology for the implementation. There are many variations of agile, two of the most popular, Scrum and Extreme Programming (XP) were considered. Scrum is a methodology that leverages a concept known as sprints. These sprints are fixed lengths of work cadences - typically one or two weeks - where development takes place and iterations are produced. Since agile underpins this software model, focus is placed on the users and assumes an empirical approach, adapting to dynamic requirements and accepting that the project cannot be fully defined from the outset [28]. Scrum has been selected for its suitability to small and medium sized projects. Since the development of this application involves a single developer, the scalable nature of Scrum fits well. Holistic sprints encompass requirements capture, development, testing and evaluation; this produces a user focused product, in line with expectations [28]. 


\subsection{Usability Eval uation}

There are a number of usability evaluation techniques including the think aloud protocol and cognitive walkthrough. Think aloud involves participants verbalising their thought processes whilst engaging and moving through the user interface [29]. Cognitive walkthrough offers insight into a system's learnability and ease of use by simulating user problems [30]. The System Usability Scale was used together with semi-structured interview to elicit an overall usability score with more detailed feedback on the various aspects of the application.

System Usability Scale (SUS) is a simple, easy to use approach for measuring the usability of a product or service. The approach consists of a ten-item questionnaire, and five response options ranging from strongly agree to strongly disagree. In order to calculate the system usability score, each question has a rating scale with a value from one to five. The answers to the odd questions are subtracted by one, the answers to odd questions are subtracted from five. The total is then multiplied by 2.5 , giving a result out of 100 [31]. SuS results were compared from 500 studies and resolved anything above 68 is considered to be above average [31].

Semi-structured interviews were conducted to gather requirements from end users and evaluate all aspects of the application. Interviews are a convenient data collection technique enabling the engagement of end-users and key stakeholders, and offer an opportunity collaboratively define the problem in depth. Outputs provide reliable, comparable and qualitative data and although they can be time consuming and resource intensive, this data proved vital throughout.

\section{$4 \quad$ Results}

\subsection{Procedure and participant profiles}

Weekly review meetings were conducted involving: the primary developer, a Human Computer Interaction (HCI) expert, and a nutrition and diet expert with experience in offering cancer related guidance. These sessions together with expert guidance helped to establish the design of the application and drove continued iterations in the development and identified improvements to be completed prior to evaluations. Throughout the design, development and evaluation process the project nutritional expert coordinated continued engagement with relevant health care professionals that care for those living with and beyond cancer. The health care professioanls $(\mathrm{n}=13)$ included dietitians $(n=9)$ and general practitioners $(n=2)$ and an oncologist $(n=1)$ with experience in offering cancer related guidance. All participants obtained a qualification including an undergraduate degree $(n=7)$, postgraduate diploma $(n=1)$ and postgraduate degree $(n=5)$. Further details about participant profiles are shown in Table 1. 
Table 1. Health Care Professional profiles.

\begin{tabular}{|c|c|c|c|c|c|c|c|c|c|c|c|}
\hline \multicolumn{12}{|c|}{ Health Care Professionals } \\
\hline ID & Gender & Age & Job & $\begin{array}{l}\text { Work in } \\
\text { Cancer/ } \\
\text { Oncology }\end{array}$ & Highest Education & Source of info on nutrition & Source details & \begin{tabular}{|l|} 
Training on \\
nutritional care \\
for cancer \\
patients
\end{tabular} & Phone usage & $0 / \mathrm{s}$ & \begin{tabular}{|l} 
Regular \\
device \\
owned
\end{tabular} \\
\hline \multirow[b]{2}{*}{$\# 1$} & \multirow[b]{2}{*}{ Female } & \multirow[b]{2}{*}{$36-45$} & \multirow[b]{2}{*}{ Dietitian } & \multirow[b]{2}{*}{ No } & \multirow{2}{*}{ 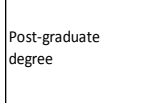 } & \multirow[b]{2}{*}{ Early influences (family and/or school) } & Training undertaken from employment & Yes & \multirow[b]{2}{*}{ Samsung A3 } & \multirow[b]{2}{*}{ Android } & Smartphone \\
\hline & & & & & & & \begin{tabular}{|l} 
Colleagues/friends \\
Academic journals \\
Degree in dietics \\
\end{tabular} & $\begin{array}{l}\text { Cancer } \\
\text { survivorship } \\
\text { PHD }\end{array}$ & & & Tablet \\
\hline$\# 2$ & Female & $36-45$ & Dietitian & Yes & Degree & Courses on diet and nutrition & & Yes & iPhone & ios & \begin{tabular}{|l|} 
Smartphone \\
Tablet \\
Laptop \\
\end{tabular} \\
\hline \multirow[t]{2}{*}{ \#3 } & \multirow[t]{2}{*}{ Female } & \multirow[t]{2}{*}{$26-35$} & \multirow[t]{2}{*}{ Dietitian } & \multirow[t]{2}{*}{ No } & \multirow[t]{2}{*}{ Post-graduate degree } & Courses on diet and nutrition & \multirow{2}{*}{ Training undertaken from employment } & \multirow[t]{2}{*}{ Yes } & \multirow[t]{2}{*}{ iPhone } & ios & Smartphone \\
\hline & & & & & & Early influences (family and/or school) & & & & iOS & Tablet \\
\hline \#4 & Female & $18-25$ & Dietitian & Yes & Degree & Courses on diet and nutrition & Training undertaken from employment & Yes & IPhone & iOs & Smartphone \\
\hline \#5 & Female & $26-35$ & Dietitian & Yes & Post-graduate degree & Courses on diet and nutrition & Training undertaken from employment & Yes & IPhone & ios & Smartphone \\
\hline$\# 6$ & Female & $36-45$ & Dietitian & Yes & Degree & Early influences (family and/or school) & Training undertaken from employment & Yes & Note 2 & Android & Smartphone \\
\hline$\# 7$ & Female & $36-45$ & Dietitian & Yes & Degree & Courses on diet and nutrition & Training undertaken from employment & Yes & IPhone & ios & Smartphone \\
\hline$\# 8$ & Female & $26-35$ & Dietitian & Yes & Diploma & Courses on diet and nutrition & Training undertaken from employment & Yes & IPhone & ios & Smartphone \\
\hline$\# 9$ & Female & $26-35$ & Dietitian & Yes & Degree & Early influences (family and/or school) & Training undertaken from employment & Yes & IPhone & ios & Smartphone \\
\hline$\# 10$ & Female & $46-55$ & Oncologist & tYes & Degree & Courses on diet and nutrition & Training undertaken from employment & Yes & IPhone & ios & Smartphone \\
\hline \#11 & Female & $36-45$ & Dietitian & Yes & Degree & Early influences (family and/or school) & Training undertaken from employment & Yes & IPhone & ios & Smartphone \\
\hline \#12 & Female & $36-45$ & GP & No & Post-graduate degree & Courses on diet and nutrition & Academic journals & Yes & IPhone & ios & Smartphone \\
\hline$\# 13$ & Male & $26-35$ & GP & No & Post-graduate degree & Early influences (family and/or school) & Training undertaken from employment & Yes & Samsung S8 & Android & Smartphone \\
\hline
\end{tabular}

These engagements helped drive content and feature design, improvements and evaluation. Each HCP participated in a semi-structured interview and completed the SUS evaluation. Only two health care professioanls contributed to Participatory Design sessions due to time limitations.

\subsection{Design Iterations}

The PD design iterations included creating a sitemap that presents the basic navigational structure of the application. Since mobile development requires a more simplistic hierarchy, a top level holistic tab navigation is used, directing users to the main navigation (Fig. 1). Feature mapping, signposting and wireframe designs were other outputs of the PD sessions. Sample resources were used for the signposting.
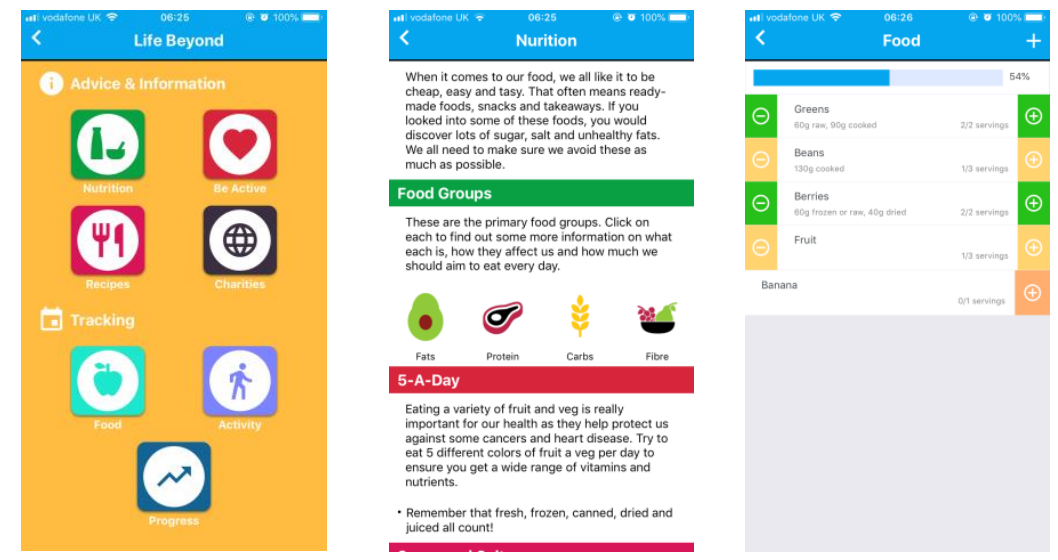

Fig. 1. Life Beyond Application User Interfaces. 
The PD design iterations resulted in designing the key features of the application as shown in Table 2.

Table 2. Key features of the application.

\begin{tabular}{|c|c|c|}
\hline Feature & Description & Rationale \\
\hline $\begin{array}{l}\text { Signposted } \\
\text { information }\end{array}$ & $\begin{array}{l}\text { A collection of evidence-based } \\
\text { guidance, a short description of } \\
\text { the information within and a } \\
\text { link to the site of origin. }\end{array}$ & $\begin{array}{l}\text { The primary offering of the application } \\
\text { according to the client's requirements } \\
\text { will be to provide a centralised store of } \\
\text { information for users. }\end{array}$ \\
\hline Slideshow & $\begin{array}{l}\text { A slideshow of images and links } \\
\text { to highlight the key, recent } \\
\text { research related to cancer and } \\
\text { nutrition/lifestyle choices. }\end{array}$ & $\begin{array}{l}\text { Slideshows offer a visual method of } \\
\text { highlighting key and important news to } \\
\text { users and have been used to effect in } \\
\text { existing M-health apps. }\end{array}$ \\
\hline $\begin{array}{l}\text { Food intake } \\
\text { tracking }\end{array}$ & $\begin{array}{l}\text { A feature that offers users the } \\
\text { ability to track a fully } \\
\text { customizable list of foods to be } \\
\text { consumed on a daily basis. }\end{array}$ & $\begin{array}{l}\text { The application must promote behavior } \\
\text { change through a number of features, as } \\
\text { required by the client. This feature offers } \\
\text { users the ability to create a list of foods } \\
\text { to consume on a daily basis and } \\
\text { incorporate the guidance (signposted to) } \\
\text { into their daily lives. }\end{array}$ \\
\hline Daily tracking & $\begin{array}{l}\text { A feature that offers users the } \\
\text { ability to track a fully } \\
\text { customizable list of daily } \\
\text { activities to be completed on a } \\
\text { daily basis. }\end{array}$ & $\begin{array}{l}\text { The application must promote behavior } \\
\text { change through a number of features as } \\
\text { required by the client. This feature offers } \\
\text { users the ability to create a list of } \\
\text { activities to complete on a daily basis } \\
\text { and incorporate the guidance (signposted } \\
\text { to) into their daily lives. }\end{array}$ \\
\hline Goal setting & $\begin{array}{l}\text { A feature that enables users to } \\
\text { set a list of custom goals related } \\
\text { to food consumption and daily } \\
\text { activities. }\end{array}$ & $\begin{array}{l}\text { Such features promote } \\
\text { completion of goals and help to shape } \\
\text { new behaviors into habits. }\end{array}$ \\
\hline $\begin{array}{l}\text { Progress } \\
\text { tracking }\end{array}$ & $\begin{array}{l}\text { A feature that enables users to } \\
\text { track their progress in } \\
\text { completing their customized } \\
\text { goals, displaying the number of } \\
\text { goals completed and the number } \\
\text { of successful days etc. }\end{array}$ & $\begin{array}{l}\text { Offering a progress tracking feature } \\
\text { enables users to sustain completion of } \\
\text { goals and helps to promote continued } \\
\text { motivation. }\end{array}$ \\
\hline Sharing Feature & $\begin{array}{l}\text { A feature that enables users to } \\
\text { share the application to their } \\
\text { friends, family and network. }\end{array}$ & $\begin{array}{l}\text { Social features and sharing capabilities } \\
\text { in behavior change applications are } \\
\text { found to be some of the most important } \\
\text { and successful features. }\end{array}$ \\
\hline
\end{tabular}

\subsection{System Usability Score (SuS) and Interview Results}

The participants $(n=13)$ were asked to complete a number of tasks within the app without guidance. This formed the task-based analysis of the evaluation and participants were asked to speak aloud their thought process, giving the authors indication to the various limitations of the application. Following the analysis, participants were asked to answer questions relating to the System Usability Scale (SuS) scoring. This usability evaluation technique is used to metricise the usability of 
a system, technology or otherwise. The answers to the questions are calculated and used to determine an overall usability (or system usability) score and can be seen below. Following is a list of tasks that participants completed.

- Find the list of nutrition information

- Find the list of exercise information

- Find the list of charitable organisations

- Find the food track behaviour change feature

- Add a new food to track

- Complete one of the tracked foods

- Find the list of daily activities to be tracked

- Add a new daily activity

- Complete one of the activities

- Find the progress screen

The average SuS score came to a total of 67.69. This represents an average system in regard to usability, with improvements to be made. That said, this application was merely a proof of concept, designed to elicit feedback and conduct initial evaluations.

Semi-structured interviews formed the final phase of each evaluation. Participants were asked a number of qualitative questions, designed to elicit more detailed feedback on the various aspects of the system. The comments received here vary in subject, however some topics highlight a number of trends. Most participants felt the application to be easy to use, colourful and conceptually, a very strong idea. However, feedback highlighted the application must be more cancer specific, accounting for specific needs of those living with and beyond cancer. Additionally, participants felt the application should be structured with less text and more pictures, giving users an aesthetically pleasing, and removing the need to trawl through large amounts of information. 


\section{Discussion}

This proof of concept of paper has, for the first time provide an application to centralize evidence-based nutrition and lifestyle guidance for health and care professionals and for people living beyond cancer. It has enabled users to obtain guidance and information create and track nutrition and activity related goals and track their progress in the completion of these goals. The findings from feedback of participatory design and usability evaluation have informed a preliminary solution that has met user expectations.

The advantages for the management of other lifestyle conditions such as diabetes, hypertension and obesity have already been demonstrated [19, 20, 32] and for the prevention of breast cancer [22] and to increase dietary intake and provide nutritional support for cancer patients [21]. However the smartphone app intervention developed and tested in this study is innovative. No other studies have provided a solution for those living with and beyond cancer treatment and who would require support and monitoring to follow healthy lifestyles to meet current WCRF recommendations [4]. However a limitation is that the app was not designed to focus on a particular type of cancer but appropriate support and guidance is enabled and signposted. What also emerged were the requirements for health care professionals that differed with those of people living with and beyond cancer in terms of the user engagement and presentation of information. As such it is important that further work considers nutrition and lifestyle information presented not only in appropriate format but also at an appropriate reading level for all individuals including those with marginal literacy skills.

\section{Conclusions and Future Work}

This study has demonstrated the potential to provide a new digital health care platform for health care professionals and people living with and beyond cancer to access nutrition and lifestyle guidance and meet lifestyle goals by changing behaviours and improve nutritional wellbeing and quality of life. Further research and extensive end user engagement is needed to confirm these initial findings and test the feasibility and applicability on a larger scale to inform an optimal solution.

\section{Acknowledgements}

The authors acknowledge the contribution of all the participants in the study and the support offered by the NIHR Cancer and Nutrition Collaboration. 


\section{References}

1. Maddams, J., Utley, M. \& Møller, H. (2012). Projections of cancer prevalence in the United Kingdom, 2010-2040. British Journal of Cancer, 107, 1195-1202.

2. Travis, L. B., Rabkin, C. S., Brown, L. M., et al. (2006). Cancer survivorship-genetic susceptibility and second primary cancers: Research strategies and recommendations. Journal of the National Cancer Institute, 98, 15-25.

3. Kassianos, A. P., Raats, M. M., Gage, H. \& Peacock, M. (2015). Quality of life and dietary changes among cancer patients: A systematic review. Quality of Life Research, 24, 705719 .

4. World Cancer Research Fund/American Institute for Cancer Research. (2018). Diet, Nutrition, Physical Activity and Cancer: a Global Perspective. Continuous Update Project expert Report. Available at https://www.wcrf.org/dietandcancer

5. Maskarinec, G., Murphy, S., Shumay, D.M. \& Kakai, H. (2001). Dietary changes among cancer survivors. European Journal of Cancer Care 10, 12-20.

6. van Weert, E., Hoekstra-Weebers, J., Grol, B., Otter, R., Arendzen, H.J., Postema, K., Sanderman, R. \& van der Schans, C. (2005). A multidimensional cancer rehabilitation program for cancer survivors - effectiveness on health related quality of life. Journal of Psychosomatic Research 58, 485-496.

7. Demark-Wahnefried, W. \& Jones, L.W. (2008). Promoting a healthy lifestyle among cancer survivors. Hematology- Oncology Clinics of North America 22, 319-342.

8. McBride, C. M. \& Ostroff, J.S. (2003) Teachable moments for promoting smoking cessation: The context of cancer care and survivorship. Cancer Control: Journal of the Moffitt Cancer Center, 10, 325-333.

9. Anderson, A., Caswell, S., Wells, M. \& Steele R.J.C. (2013). Obesity and lifestyle advice in colorectal cancer survivors-How well are clinicians prepared? Colorectal Disease, 15, 949-957.

10. Beeken, R.J., Williams, K., Wardle, J. \& Croker, H. (2016). "What about diet?" A qualitative study of cancer survivors' views on diet and cancer and their sources of information. Eur J Cancer Care (Engl). 2016 Sep; 25(5): 774-83

11. Jones, L.W. \& Demark-Wahnefried, W. (2006). Diet, exercise, and complementary therapies after primary treatment for cancer. Lancet Oncology 7, 1017-1026.

12. Van Tonder, E., Herselman, M.G. \& Visser, J. (2009). The prevalence of dietary related complementary and alternative therapies and their perceived usefulness among cancer patients. Journal of Human Nutrition and Dietetics 22, 528-535.

13. Cancer and Nutrition NIHR infrastructure Collaboration - Summary of Phase one July 2015 http://cancerandnutrition.nihr.ac.uk/

14. Corfe, B.M, Murphy, J.L., Davey, F.P. et al. (2018). Nutritional screening, assessment and provision of advice for people living with and beyond cancer - a UK survey of clinicians. Proceedings of the Nutrition Society (2018), 77 (OCE1), E25

15. MyFitnessPal Inc. (2018). MyFitnessPal (Version 18.11.5) [Mobile application software]. Retrieved from https://www.apple.com/uk/ios/app-store/.

16. NutritionFacts.org, (2018). Daily Dozen (Version 2.0) [Mobile application software]. Retrieved from https://www.apple.com/uk/ios/app-store/.

17. WebMD, LLC. (2017). Medscape (Version 5.13) [Mobile application software]. Retrieved from https://www.apple.com/uk/ios/app-store/.

18. Burke, L. E., Conroy, M. B., Sereika, S.M., Elci, O.U., Styn, M.A., Acharya, S.D. et al. (2011). The effect of electronic self-monitoring onweight loss and dietary intake: a randomized behavioral weight loss trial. Obesity (Silver Spring), 19(2): 338-344 [doi: 10.1038/oby.2010.208].

19. Finkelstein, J., Bedra, M., Li, X., Wood, J., Ouyang, P. (2015). Mobile app to reduce inactivity in sedentary overweight women. Study Health Technology Inform, 216: 89-92 
20. Ryan, E.A., Holland, J., Stroulia, E., Bazelli, B., Babwik, S.A., Li H., et al. (2017). Improved A1C levels in type 1 diabetes with smartphone app use. Can J Diabetes, 41(1): 33-40. [doi: 10.1016/j.jcjd.2016.06.001].

21. Coughlin, S.S., Besenyi, G.M., Bowen, D., De Leo, G. (2017). Development of the Physical activity and Your Nutrition for Cancer (PYNC) smartphone app for preventing breast cancer in women. Mhealth; 3:5 [doi:10.21037/mhealth.2017.02.02].

22. Orleman, T., Reljic Zenker, D., Meyer, J., Eskofier, B., Thiemt, J., Herrmann, H., Neurath M.F., Zopf Y. (2018). A Novel Mobile Phone App (OncoFood) to Record and Optimize the Dietary Behavior of Oncologic Patients: Pilot Study. JMIR Cancer, 4(2): [doi:10.2196/10703].

23. Peng, W., Kanthawala, S., Yuan, S. and Hussain, S. (2016). A qualitative study of user perceptions of mobile health apps. BMC Public Health, 16 (1).

24. Anderson, K., Burford, O. and Emmerton, L. (2016). Mobile Health Apps to Facilitate Self-Care: A Qualitative Study of User Experiences. PLOS ONE, 11 (5), e0156164.

25. Krug, S. (2014). Don't Make Me Think, Revisited. Berkeley: New Riders.

26. Muller, M. J. (2003). Participatory design: the third space in HCI. Human-computer interaction: Development process 4235 (2003): 165-185.

27. Fairbanks, B., Pulman, A., Dogan, H., Jiang, N., Pretty, K., Thomas, P. and Thomas, S., (2018). Creating a FACETS digital toolkit to promote quality of life of people with multiple sclerosis through Participatory Design. In: 2nd Workshop on Human Centred Design for Intelligent Environments (HCD4IE). The 32nd Human Computer Interaction Conference (British HCI'18) 3 July 2018 Belfast.

28. Agile PrepCast. (2015). Comparison of Agile Methods by The Agile PrepCast [online]. Project Management Prepcast.

29. Nielsen, J., 2012. Thinking Aloud: The \#1 Usability Tool. Nielsen Norman Group, Available from: https://www.nngroup.com/articles/thinking-aloud-the-1-usability-tool/.

30. Spencer, R. (2000). The streamlined cognitive walkthrough method, working around social constraints encountered in a software development company. Proceedings from ACM CHI 2000: Conference on Human Factors in Computing Systems. New York: ACM Press.

31. MeasuringU, (2011). Measuring Usability with the System Usability Scale (SUS) [online]. MeasuringU, Available from: https://measuringu.com/sus/ [Accessed 1 March 2018].

32. Kang, H. \& Park. H. (2016). A mobile app for hypertension management based on clinical practice guidelines: development and deployment. JMIR Mhealth Uhealth, 4(1):e12 [doi: 10.2196/mhealth.4966]. 